\title{
The Effect of Electric Blackout on the Operation and Productivity of Small Manufacturing Enterprises
}

\author{
Ephrem Ahadu \\ Department of Civics and Ethical Studies, Wachemo University, Po box 667, Hosaena, Ethiopia
}

\begin{abstract}
The contribution of electricity to improve the productivity and efficiency of small enterprises is indispensable. The general objective of the research is to understand the effect of electric blackout on the operation and productivity of some selected small manufacturing enterprises in District 12, Nifas Silk Lafto Sub-city of Addis Ababa. Small enterprises experience frequent and unannounced electric blackouts. Frequent and unannounced electric blackouts affect small enterprises ability to meet contract deadlines. The cost of a power outage which lasts for three hours and above is higher than for a power outage which lasts for less than three hours. However, a blackout which stays even for a shorter time has a huge impact on the small enterprises overall activity, employees work motivation and productivity. To reduce the electric blackout that occurs too frequently, the government has to improve the reliability of the electric supply by reducing technical faults in the transmission and distribution of the infrastructure as well as increasing the electricity generating capacity of the power station. Keywords: Electric,Blackout,SMEs,Productivity,Operation
\end{abstract}

DOI: $10.7176 / \mathrm{JETP} / 9-6-01$

Publication date: August $31^{\text {st }} 2019$

\subsection{Introduction}

Micro and small scale enterprises contribute significantly to employment creation, income and revenue generation, and overall poverty reduction in developing countries (Aremu \& Adeyemi, 2011). Kayanula and Quartey (2000) and NDPC (2003) add that the MSI sector plays an indispensable role in driving developing countries' engines of growth. The labour intensive nature of MSI is the explanation for the significant roles they play in national development (Albaladejo, 2000 cited in UN, 2006). The development of large corporations in developing countries is highly dependent on the presence of MSE. Rostow explains this in "the Process of Economic Growth" and the "Stages of Economic Growth". He argues that the dynamics of industries usually starts with a takeoff (small or medium scale but efficient) and then moves to technological maturity, usually associated with high mass consumption (large scale firms that employ high level of factors of production). In sum, MSE play significant roles in national development.

The contribution of electricity to improve the productivity and efficiency of small enterprises is huge. However, a series of electric blackout affect the productivity of these enterprises. Meadows (2003) claims that "electricity is one of the critical elements needed to improve micro and small enterprises from low value, low productivity and low income activities."

Ethiopia is currently suffering from energy crisis. An inadequate supply of electricity along with unpredictable security situation is one of the major problems that residentsand enterprises are facing. Power outages have become a common occurrence in the region for a number of years. Although the relevance of the power outages problem in Addis Ababa is undeniable,there is no existing literature on this issue. The aim of this paper is, therefore, to show how electric blackout affects small enterprises through collected survey data in District 12 of Nifas Silk Lafto Sub-city.

\subsection{Statement of the Problem}

Electric energy is one of a number of critical enabling factors necessary for micro-enterprise development. However, it is a crucial input missing in developing countries, especially in sub-Saharan Africa. Only $29 \%$ of people living in sub-Saharan Africa have access to electricity compered to half of South Asians and over $80 \%$ of Latin Americans, Middle Eastern and North Africans (World Bank, 2010). Many development experts believe that there is much to gain from the spread of electricity: increasing work productivity; enhancing health services; facilitating household investments in education, by extending the time students could devote to studying; and improving household health, by providing a low pollution alternative to cooking with firewood or charcoal (World Bank, 2008).

Manufacturing industries including small and micro-enterprises need to have electric power for their operation. For these industries power supply is vital for their existence and productivity. A reliable power supply maximizes the productivity of the enterprises because it enables the enterprises to utilize all its resources on the contrary; unreliable power supply affects the operation of the enterprises and their productivity. According to the World Bank (2010) report, one of the most impeding factors to the performance businesses in the sub-Saharan Africa is the availability of crucial infrastructure such as electricity and water. Electricity is considered by far the 
greatest hindrance by businesses in Sub-Saharan Africa. Without available and reliable electricity services there is no possibility of utilizing modern electrical appliances, welding kits, and machinery which may pave the way to small and cottage industries. There is also no convenient lighting in businesses such as bars and retail shops, which reduces the number of customers. Moreover, society`s growing reliance on digital circuitry has made even a short disruptions power supply potentially costly (Medows, 2003). Such power disturbances pose problems not only for internet café but also for enterprises reliant on electricity.

Since access to reliable electricity is one of the most critical elements of development, conducting research on this issue will be imperative to show the extent to which electric blackout affects the operation and productivity of small enterprises. In addition to this, the findings of this research will give an insight to practitioners and policy makers in developing appropriate policy and strategy to tackle this developmental problem.

\subsection{Objectives of the Study}

The general objective of this research is to understand the effect of electric blackout on the operation and productivity of some selected small manufacturing enterprises in District 12, Nifas Silk Lafto Sub-city of Addis Ababa, Ethiopia. This general objective has the following specific objectives:

\# To assess the effect of electric blackout on the operation of small manufacturing enterprises.

$\$$ To estimate the cost of a brief outages on small manufacturing enterprises.

* To provide a solid foundation for discussions of what actions policy makers should take to ensure more reliable power for enterprises.

\subsection{Research Questions}

$\checkmark \quad$ What is the effect of electric blackout on the operation of small manufacturing enterprises?

$\checkmark$ How much is the cost of a brief outage on small manufacturing enterprises?

$\checkmark \quad$ What action shall the government take in order to halve the problem of electricity?

\subsection{Scope of the Study}

The scope of this study is limited to studying few selected small enterprises of District 12, Nifas Silk Lafto Subcity. The study used the manufacturing sector of small enterprise particularly metal and woodwork businesses to analyze the effect of electric blackout on their operation and productivity.

\subsection{Conceptual Framework of the study}

Definition, Causes and Consequences of power outage

The term power outage refers to a short or long-term loss (supply interruption) of electric power [Eto et al. (2001)]. There are many different factors that may cause power outages. Simonoff et al. (2005) distinguish between the following ones: (i) crime (ii) equipment failure (iii) fire (iv) human error (v) operational error (vi) natural disaster (vii) weather (viii) third party (ix) unknown and (x) capacity shortage. According to his results, equipment failure and weather are the most frequent power outage incidents in the USA. However for many developing countries, including Pakistan, energy shortages leading to load-shedding represent the number one factor for outage cause.

Most of the time power outage is not caused by a single event but also others. Michael Bruch (2011) stated that typically power blackouts are not caused by a single event but by a combination of several deficiencies. 


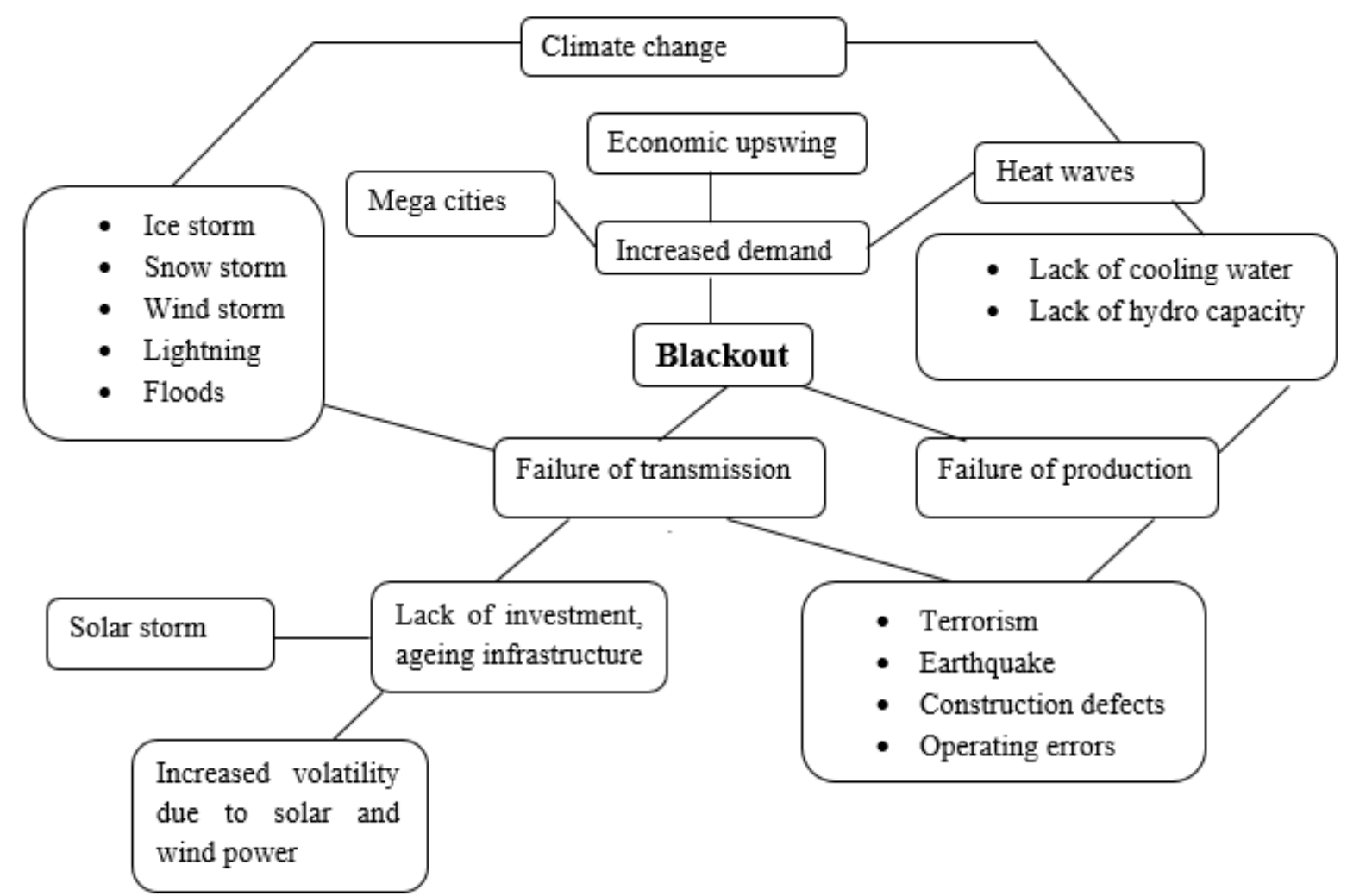

Figure 2: Potential causes of power blackouts by CRO

Electric blackout has direct and indirect costs. Michael Bruch (2011) identified the direct and indirect costs of electric blackout on different sectors. The direct costs of blackouts are lost production, idle labour and facilities, damage to electronic data, spoiled food and damaged products, damage to equipment or customer refunds whereas the indirect costs are looting, accidental injuries, legal costs and loss of water supply. 


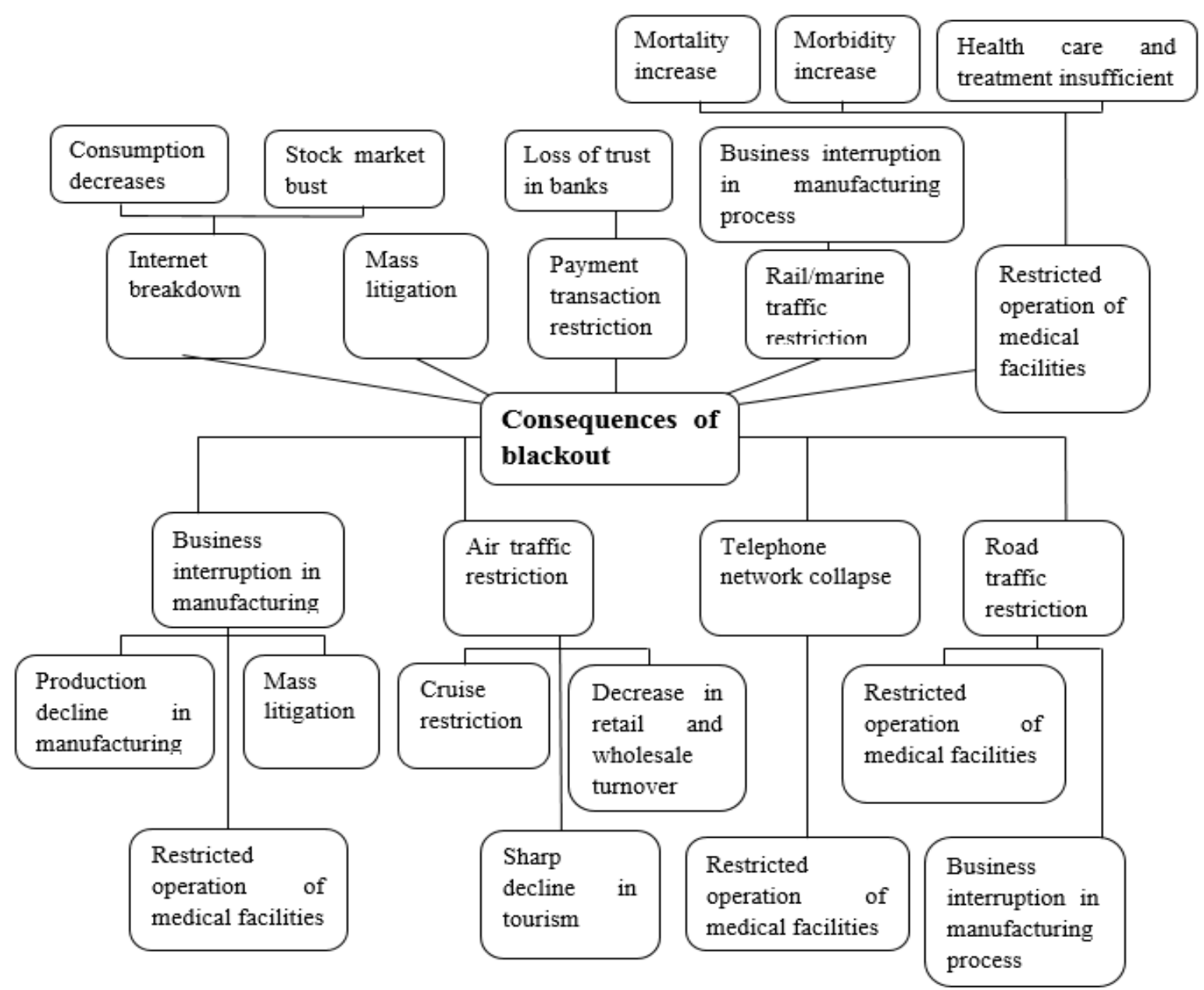

Figure 3: Consequences of blackout by CRO

\section{RESEARCH METHODOLOGY}

This chapter outlines the study area, study design, study subject, sampling size, sampling method, method of data collection, description of variables, data quality assurance and method of data analysis. 


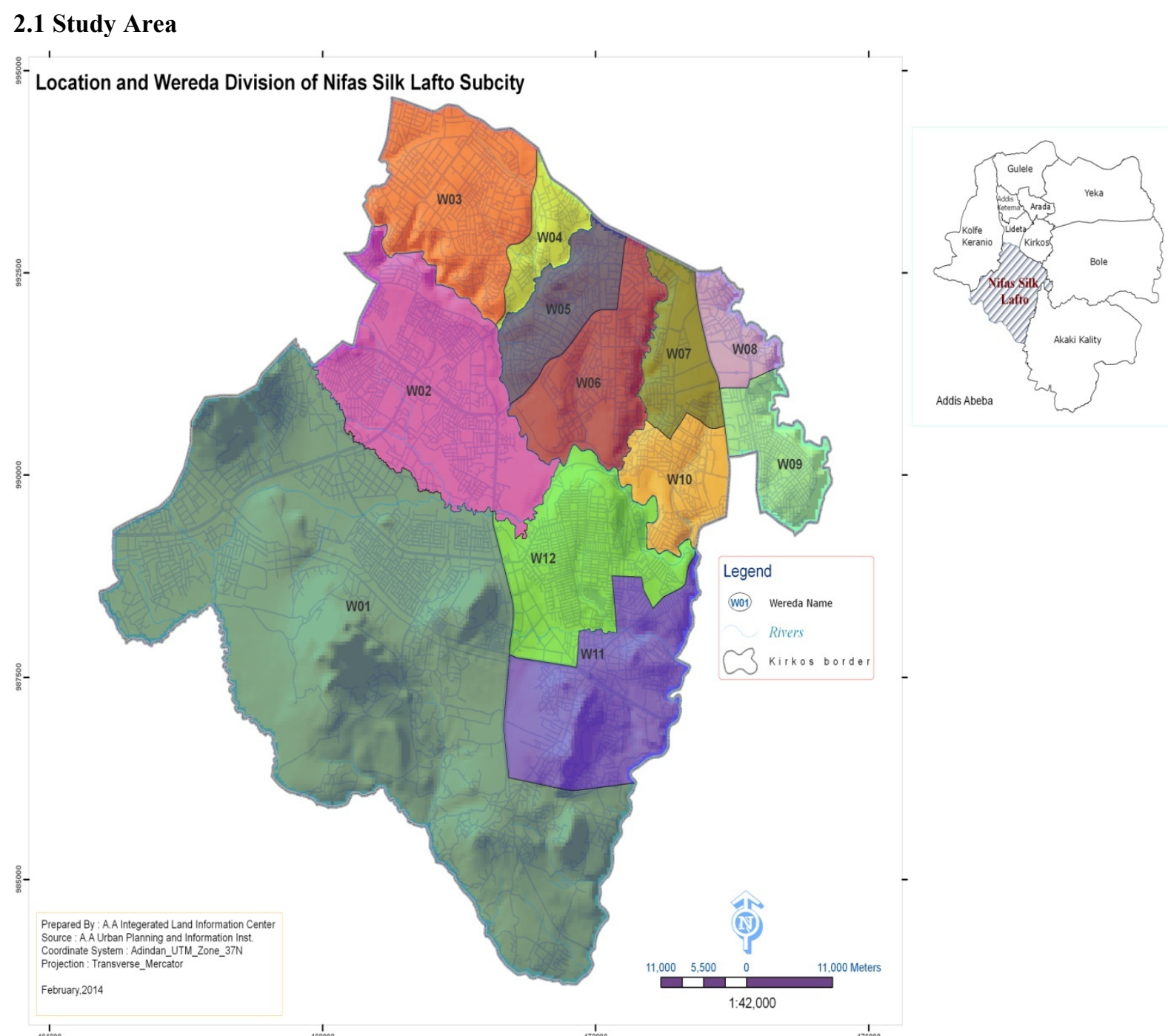

Figure 1: Location and Woreda Divisions of Nifas Silk Lafto Sub-city

Nifas Silk Lafto is one of the ten sub-cities in Addis Ababa alongside Kolfe Keraneo, Kirkos, Lideta, Arada, Gulele, Akaki Kaliti, Addis Ketema, Yeka and Bole Sub-cities. Geographically Nifas Silk Lafto Sub-City is located at $8^{0} 57^{\prime} 41.76^{\prime \prime} \mathrm{N}$ latitude and $38^{\circ} 43^{\prime} 39^{\prime \prime} \mathrm{E}$ longitude. It is situated in the southwestern suburb of the city at an elevation of about 2,440m (about 8000ft) above sea level. Based on the 2007 Census conducted by the Central Statistical Agency of Ethiopia (CSA), Nifas Silk Lafto Sub-city has a total population of 316,283, of which 148,984 are men and 167,299 women.In Nifas Silk Lafto Sub-city there are 12 Districts. From these Districts the focus area of this research is District 12. District 12 is located south of District 6, north of District 11, west of District 1, southeast of District 2 and southwest of District 10.The main reason the researcher selected this area is because he lives in this part of the city and knows the extent to which electric blackout affects the activities of small enterprises in this District. Although the focus area of this research is District 12, NSLSC, the researcher believes that power outage is perhaps the same problem in other Districts and Sub-cities as well.

\subsection{Study Design}

As samples, the researcher selected 10 small manufacturing enterprises all of which were engaged in Metal and Woodwork businesses from District 12, Nifas Silk Lafto Sub-city. This study employed a survey based approach to assess the effect of electric blackout and to estimate the costs of a brief outage on small manufacturing enterprises. A sample of 10 small enterprises from District 12 is surveyed to assess the frequency and duration of power outages and its effect on the operation of their enterprises. Survey respondents were also given two outage scenarios, each describing a hypothetical outage striking facility at a specific time, for a specific duration, without advance warning. In this research only two outage scenarios are used to make the questionnaire easy and manageable to the respondents and to get more and reliable information. For each outage scenarios, survey respondents estimate the costs they would incur from various sources, including idled labor, material loss, 
equipment damage and lost production or sales. These data provided the basis for assessing the effect of electric blackout on the operation and productivity of small enterprises based on how many outages of various lengths they experience; and the total cost of power outages phenomena to the 10 small manufacturing enterprises of District 12,Nifas Silk Lafto Sub-city.

\subsection{Sample Size}

The sample size this research used to show the effect of electric blackout on the operation and productivity of small manufacturing enterprises is 10 . Even though the researcher is aware that the sample size is too small, he has deliberately chosen this sample size for two reasons. The first reason is as there has been no research conducted on this issue, the researcher believes that this preliminary study will show the extent to which electric blackout affects small enterprises operation and productivity. The other reason of using this number of samples is to initiate other researchers to use this study as spring board to conduct other comprehensive and extensive research on this area.

\subsection{Sampling Method}

The sampling method that the researcher used to select the variables is convenience sampling method. This sampling method is chosen because it is considered more appropriate to the issue which is studied and all the variables are more conveniently available.

\subsection{Method of Data Collection}

The researcher used structured questionnaire and semi structured interview in order to collect datafrom the 10 samples of small manufacturing enterprises. Compared to other data collection tools, they are more convenient to gather the required information from the respondents in study.The questionnaire is framed in such a way that it entails both close and open ended types of questions. The questionnaires have been pretested and modified as well before conducting the survey. During the pilot test of the questionnaire, 20 owners of small enterprises were selected through convenience sampling. The researcher administered the questionnaire in the month of March 2018/19. Semi-structured interviews were conducted by taking 10 samples from the owners of small enterprises and their employees. These sample respondents were selected using convenience sampling. Such interviews with these sample respondents were undertaken believing that they would help the researcher in finding out the necessary information about the study.

\subsection{Data Quality Assurance}

In order to maintain the quality of data, the researcher accomplished the following tasks:Gave orientation to the respondents before distributing the questionnaire. Doing this would make the respondents give due attention to the significance of providing quality data and the importance of being responsible when filling in the questionnaire. Analyzed the data which was collected from the respondents professionally and objectively based on the data, not by personal preference. The researcher fully understands the negative effect of false information and inaccurate data analysis.

In addition to this, all of the information was processed by the researcher, starting from giving orientation, collecting questionnaire, analyzing and interpreting the data in order to increase the reliability and the quality of the data.

\subsection{Method of Data Analysis}

The effect of electric blackout on the operation of small manufacturing enterprises is analyzed in terms of the frequency and duration of power outage, the property damage, the ability to meet contract deadline and the availability of backup generator to deal with power reliability concerns. The costs that the small enterprises incurred as a result of the electric blackout was analyzed by using direct costing approach which is widely used to estimate the real economic impact of power disruption.

\section{RESULTS AND DISCUSSIONS}

Finally the data obtained from the survey respondents was analyzed both qualitatively and quantitatively.

\subsection{A Brief Profile of Ten Small Manufacturing Enterprises}

The ten small manufacturing enterprises were established in 2002 and 2003 in Nifas Silk Lafto Sub city. These small enterprises began their operation with different initial capitals and number of employees. Currently, these small enterprises have different capital and number of employees. At the moment these small manufacturing enterprises are generating income, creating employment opportunity, paying tax and contributing a lot to the local economy. 


\subsection{The Effects of Electric Blackout on the Operation of Small Enterprises}

Under this section, the effect of electric blackout on the operation of small manufacturing enterprises is analyzed in terms of the frequency and duration of the power outage, the property damage, the ability to meet contract deadline and the availability of backup generator to deal with power reliability concerns.

Table 1: The frequency of the power outage in a month and its duration in percent

\begin{tabular}{|l|l|l|l|}
\hline $\begin{array}{l}\text { Small enterprise } \\
\text { owners }\end{array}$ & $\begin{array}{l}\text { Frequency of power } \\
\text { outage in a month }\end{array}$ & $\begin{array}{l}\text { Power outage in a month which } \\
\text { lasts for less than 3hrs(in percent) }\end{array}$ & $\begin{array}{l}\text { Power outage in a month which } \\
\text { lasts for 3hrs and above( in } \\
\text { percent) }\end{array}$ \\
\hline Mehari & 15 & 30 & 70 \\
\hline Abrha & 15 & 25 & 75 \\
\hline Habtom & 18 & 64 & 36 \\
\hline Tesfatsion & 20 & 40 & 60 \\
\hline Fisiha & 11 & 60 & 40 \\
\hline Getnet & 18 & 40 & 60 \\
\hline Leuel & 16 & 8 & 20 \\
\hline Fikru & 16 & 50 & 50 \\
\hline Dawit & 15 & 40 & 60 \\
\hline Sintayehu & 12 & 55 & 45 \\
\hline Soure: & &
\end{tabular}

Source: Author's own survey

Table 1 shows the frequency and duration of the power outage that the ten small manufacturing enterprises wouldexpect toexperience at their establishments in a month. For instance, Tesfatsion, Habtom and Getnet small enterprises relatively experience large number of electric blackouts in a month i.e. 20, 18 and 18 times respectively whereas Fisiha and Sintayehu small enterprises relatively experience a small number of power outage in a month i.e. 11 and 12 times respectively.

Regarding the duration of the power outage, most of the small enterprises experience a power outage which lasts for a longer hours. For instance, Abrha and Mehari small enterprises experience relatively large number of power outages which lasts for three hours and above whereas Leuel and Habtom small enterprises experience relatively a large number of power outage which lasts for less than three hours.

From this we can understand that all small enterprises experience frequent electric blackouts at their establishments. However, the frequency and duration of power outage that they experience is different.

Table 2: Electric blackout with advanced notification

\begin{tabular}{|l|l|c|}
\hline \multirow{2}{*}{ Small enterprise owners } & Electric blackouts occur in advanced notification \\
\cline { 2 - 3 } & Yes & No \\
\hline Mehari & & $\checkmark$ \\
\hline Abrha & & $\checkmark$ \\
\hline Habtom & & $\checkmark$ \\
\hline Tesfatsion & & $\checkmark$ \\
\hline Fisiha & & $\checkmark$ \\
\hline Getnet & & $\checkmark$ \\
\hline Leuel & & $\checkmark$ \\
\hline Fikru & & $\checkmark$ \\
\hline Dawit & & $\checkmark$ \\
\hline Sintayehu & & \multicolumn{2}{|c|}{} \\
\hline
\end{tabular}

Source: Author's own survey

As is shown in table 2, all small enterprises experience electric blackout without any advanced notification. This means that these small enterprises do not have any chance to minimize the effect of electric blackout on their business activities and to plan production around outages. 
Table 3: The effect of electric blackout on machineries

\begin{tabular}{|l|c|l|l|}
\hline \multirow{2}{*}{ Small enterprise owners } & Machineries repair in a month & \multirow{2}{*}{$\begin{array}{l}\text { Number of times machineries } \\
\text { repaired in a month }\end{array}$} \\
\cline { 2 - 3 } & Yes & No & Twice \\
\hline Mehari & $\checkmark$ & & Once \\
\hline Abrha & $\checkmark$ & & Once \\
\hline Habtom & $\checkmark$ & & Twice \\
\hline Tesfatision & $\checkmark$ & & Twice \\
\hline Fisiha & $\checkmark$ & & Once \\
\hline Getnet & $\checkmark$ & & Once \\
\hline Leuel & $\checkmark$ & & Twice \\
\hline Fikru & $\checkmark$ & & Once \\
\hline Dawit & $\checkmark$ & & Once \\
\hline Sintayehu & $\checkmark$ & \\
\hline
\end{tabular}

Source: Author's own survey

As is shown in table 3, all small enterprise owners responded that their machineries are affected by the frequent nature of electric blackouts. Moreover, the results of the interview regarding this issue are presented below:

- Ato Mehari replied that he had repaired machinery twice even during data collection in March, 2018/19. He argued that the frequent machinery breakdowns were the results of the frequent and unannounced blackouts. He said "I was sawing wood when there was a blackout. When power was restored about one hour later, the electric saw I was using before the outage failed to respond. I am convinced that the fault was caused by the blackout and nothing else.

- Ato Abrha`s metal and woodwork enterprise experience property damage due to electric blackouts at least once in a month. Ato Abrha said "The frequent and unannounced electric blackouts which occur in my enterprise forced me to repair machineries at least one times in a month."

- Ato Tesfatsion repairs machineries twice in a month due to frequent and unannounced electric blackout. He said "I repaired machineries many times so far which are failed to respond, on average I repair machineries twice in a month. The reason for machineries failed to respond at the enterprise is the nature of electric blackout which occurs too frequently without any advanced notification."

- Ato Fisiha is forced to repair machineries at his enterprise on average two times in a month. He said " $I$ repair one or two of my woodwork machineries twice in a month due to the power outage which comes and goes too frequently."

- Ato Fikru is forced to repair machineries at his enterprise on average two times in a month. He said "The frequent electric blackouts which occur in my enterprise caused some of the machineries fail to respond. As a result of this, I am forced to repair machineries at least twice in a month."

- Small enterprise owners such as Getnet, Leuel, Dawit and Sintayehu also respond that they usually repair their machineries once in a month due to the frequent electric blackouts which occur at their establishments.

This entails us that all small enterprises' machineries are affected by the frequent nature of electric blackouts. As a result of this, all small enterprise owners are forced to repair machineries at their establishments either one or two times in a month.

\subsubsection{The Effect of Electric Blackout on the Operation of Small Enterprises (A Summary of 10 Small Manufacturing Enterprises)}

Table 7: The frequency of power outages in a month

\begin{tabular}{|l|l|}
\hline Number of small enterprise & Average number of monthly outages \\
\hline 10 & 15 \\
\hline
\end{tabular}

Source: Author's own survey, 2018/19.

Table 7 shows that the ten small enterprises experience power outages on average for 15 days in a month. This means that these small enterprises experience electric a blackout one in two days. 
Table 8: The duration of power outages in a month

Length of power outage

Less than 3 hours

3 hours and above

Source: Author's own survey, 2018/19.

The table above depicts that a power outage which lasts for less than three hours in a month accounts $48 \%$ whereas a power outages which lasts for 3 hours and above accounts $52 \%$ in a month. This implies the largest number of power outages that the small enterprises experience lasts relatively for a longer hours.

Table 9: Electric blackouts with advanced notification

\begin{tabular}{|l|l|}
\hline Blackouts occur in advanced notification & Respondents in percent \\
\hline Yes & 0 \\
\hline No & 100 \\
\hline Total & 100 \\
\hline
\end{tabular}

Source: Author's own survey, 2018/19.

Table 9 shows that electric blackouts which occur at the small enterprises without any advanced notification. This affects small enterprises`activities, because they do not have any chance to plan production around power outages.

Table 10: The effect of electric blackout on machineries

\begin{tabular}{|l|l|}
\hline Number of times machineries repaired & Number of respondents in percent \\
\hline One times & 60 \\
\hline Two times & 40 \\
\hline More than two times & 0 \\
\hline Total & 100 \\
\hline
\end{tabular}

Source: Author's own survey, 2018/19.

The frequent nature of electric blackout affects small enterprises ' machinery. Table 10 shows that $60 \%$ of small enterprise owners are forced to repair machineries at their enterprises once in a month whereas the remaining $40 \%$ of small enterprise owners are forced to repair machineries at their enterprises twice in a month. This means that small enterprises repair machineries at their establishments at least once in a month.

Availability of backup generator to deal with power reliability concerns -All small enterprise owners except Getnet and Sintayehu which are studied in this research do not have a backup generator to deal with power reliability concerns. Financial constraint is the major reason which is given by the small enterprise owners not to install an alternative energy source at their enterprises.

Enterprises' ability to meet contract deadlines- All the small enterprise owners are unable to meet contract deadline due to the electric blackout which occurs too frequently at their establishments.

The Effect of Electric Blackout on Employees`Work Motivation and Productivity- Small enterprise owners and their employees replied that the electric blackouts which occur too frequently at their establishments affect their work motivation.

Small enterprise owners` perception of power reliability- All the small enterprise owners are unsatisfied with the overall power reliability that their enterprises experience at the moment.

\subsection{Estimated Cost of a Brief Outage on Small Enterprises}

\subsubsection{Case one: A power outage which lasts for less than 3 hours}

The disruptive level of a power outage which lasts for this length of hours- A power outage which lasts for this length of hours is disruptive for most of small enterprises.

The effect of electric blackout on the production of the enterprises- Small enterprises' production output is slowdown at a different level and the value of production and sales that the small enterprises would be lost while activities slowdown is also different.

The possibility of the enterprises to make up the lost production- Four small enterprises (Abrha, Habtom, Getnet and Sintayehu) would make up some proportion of the lost production and sales while business activities stopped or slowdown either by running extra shifts or by giving the work in contract whereas the other small enterprises would not make up the lost production.

The estimated cost of labor due to this length of power outage - The labour cost that the ten small enterprises would expect to experience to the idle labour who are unable to work is on average 140 birr in a day whereas the labour cost that the four small enterprises would expect to experience to make up the lost production is on average 155 birr in a day.

3.3.2 Case two: A power outage which lasts for 3 hours and above

The disruptive level of a power outage which lasts for this length of hours - A power outage which lasts for this length of hours is very disruptive to all the small manufacturing enterprises. 
The effect of electric blackout on the production of the small enterprises- Small enterprises' production output is slowdown at a different level. As a result of this, the value of production and sales that the small enterprises would be lost while activities slowdown at a different level is also different.

The possibility of the enterprises to make up the lost production- Six small enterprises` ( Mehari, Tesfatsion, Fisiha, Leuel, Fikru and Dawit) lost production and sales would not likely be made up by running extra shifts or by any other methods whereas the remaining four small enterprises' would make up some proportion of the lost production and sales by running extra shifts and by giving the work in contract.

Estimated cost of labor due to this length of power outage- The labour cost that the ten small enterprises would expect to experience to the idle labour who are unable to work on average is 280 birr in a day whereas the labour cost that the four small enterprises would expect to experience to make up the lost production and sales on average is 155 birr in a day.

Estimated cost of material in a month- The material cost that the ten small manufacturing enterprises would expect to experience either to repair or replace the damaged property due to the frequent and unannounced electric blackouts on average is 2,450 birr in a month.

The total cost of power outage in a month- The total cost that the ten small enterprises would expect to experience as a result of all power outages or interruption regardless of length is on average approximately 14,900 birr in a month.

\subsection{CONCLUSIONS}

Small enterprises experience frequent and unannounced electric blackouts. Frequent and unannounced electric blackouts caused small enterprises' machineries failed to respond and business activities slowdown. Frequent and unannounced electric blackouts affect small enterprises' ability to meet contract deadlines. Small enterprise owners are unsatisfied with the overall power reliability that their small enterprises experience at the moment. The cost of a power outage which lasts for less than three hours and above three hours is different. The cost of a power outage which lasts for three hours and above is higher than for a power outage which lasts for less than three hours. However, a blackout which stays even for a shorter time has a huge impact on the small enterprises overall activity, employees work motivation and productivity. Most of the small enterprises which are studied in this research do not have a backup generator to deal with power reliability concerns. Financial constraint is the major factor which is given by the enterprise owners not to install an alternative energy source at their establishments.

\subsection{Recommendations}

To reduce the electric blackout that occurs too frequently, the government has to improve the reliability of the electric supply by reducing technical faults in the transmission and distribution of the infrastructure as well as increasing the electricity generating capacity of the power station.Government has to help small enterprises by providing reliable load shedding schedules. It is very important when unreliability of power outage is caused by lack of generation capacity, and gaps between demand and supply. The government has to improve access to an alternative electricity source for small enterprises by reducing the investment costs, measures such as credit schemes, tax or duty concessions, and shared ownership arrangements should be considered as well.Sharing backup generators is also another option to deal with power reliability concerns.Policy makers and government have to create a better environment for small enterprises to work beyond the normal working hours.

The researcher recommends the exploitation of the potential sources of electricity towards the diversification of Ethiopia's electricity generation-mix. Energy sources such as thermal, wind and others can supplement the electricity generation capacity of the country.

\section{Acknowledgment}

The Sponsor of this research is Addis Ababa University and I would like to give credit for that.

\section{Conflict of Interest}

The Author has no any conflict of interest

\section{REFERENCES}

Adenikinju, A. (2005). Analysis of the cost of infrastructure failures in a developing economy: The case of the electricity sector in Nigeria, AERC Research Paper 148, African Economic Research Consortium, Nairobi.

Amin, M. (2003). North America's electricity infrastructure: Are we ready for more perfect storms? IEEE Security and Privacy. Volume 1, Issue 5, Pages 19-25. ISSN: 15407993.

Aremu, M. A., \& Adeyemi, S. (2011). Small and Medium Scale Enterprises as a Survival Strategy for Employment Generation in Nigeria. Journal of Sustainable Development, 4 (1), 200 - 206. http://dx.doi.org/10.5539/jsd.v4n1p200 
Arnold, J., A. Mattoo and G. Narciso (2006). Services, Inputs and Firm Productivity in Sub-Saharan Africa Evidence from Firm-Level Data, World Bank Policy Research Working Paper 4048.

Eto, J., Koomey J., Lehman B. Martin N. et al. (2001). Scoping Study on Trends in the Economic Value of Electricity Reliability to the U . S . Economy, LBNL-47911

International Energy Agency (IEA) (2002). World Energy Outlook, part C, Special issues arising from the outlook, Paris, ISBN 92-64-19835-0

International Energy Agency (IEA) (2011). Advantage Energy, Emerging Economies, Developing Countries and the Private-Public Sector Interface,United Nations Global Compact

Isaksson, A. (2009). Energy Infrastructure and Industrial Development, Research and Statistics Branch Programme Coordination and Field Operations Division UNIDO, WORKING PAPER 12/2009

Kanagawa, M., \& Nakata, T. (2008). Assessment of access to electricity and the socioeconomic impacts in rural areas of developing countries. Energy Policy, 36(6), 2016-2029.

Karekezi, S., Kimani, J. (2002). Status of power sector reform in Africa: impact on the poor. Energy Policy 30 , 923-945.

Kaseke, N. and Hosking, S. (2013). Sub-Saharan Africa Electricity Supply Inadequacy: Implications Eastern Africa Social Science Research Review, Volume 29, Number 2, pp. 113-132.

Kessides, C. 1993. The Contributions of Infrastructure to Economic Development: A Review of Experience and Policy Implications. World Bank Discussion Papers No. 213. The World Bank.

Kirubi, C. and Jacobson, A. and Kammen, D. M. and Mills, A. (2009): Community-Based Electric Micro-Grids Can Contribute to Rural Development: Evidence from Kenya. World Development, 73, pp. 1208-1221.

Meadows, K., Riley, C., Rao, G., Harris, P., 2003, “Modern Energy: Impacts on Micro enterprises.” A report produced for UK Department for International Development. UK.

Michael Bruch (2011). Power blackout risks: Risk Management Options: CRO Forum, Amsterdam, Netherlands.

Simonoff, J.S., Zimmerman R., Restrepo C.E. et al. (2005). Electricity Case: Statistical Analysis of Electric Power Outages, CREATE Report \#05-013, New York University- Wagner Graduate School

Steel, W.F. and L.M. Webster. 1991. Small Enterprises under Adjustment in Ghana. World Bank Technical Paper No. 138. The World Bank, Washington, D.C.

United Nations (2011). World Population Prospects: The 2010 Revision, [online] accessed on 12/5/2013, $<$ http://esa.un.org/wpp/Excel-Data/mortality.htm>

United Nations (2013b): Main Page - 2012 - International Year of Sustainable Energy for All [online], accessed on 12/05/2013, <http://www.un.org/en/events/sustainableenergyforall index.shtml>

USAID. 1998. Power Shortages in Developing Countries: Magnitude, Impacts, Solutions, and the Role of the Private Sector. United States Agency for International Development Report to Congress. March.

World Bank (2008). The Welfare Impact of Rural Electrification: A Reassessment of the Costs and Benefits, An IEG Impact Evaluation, ISBN-13: 978-0-8213-7367-5

World Bank (2010) Getting Electricity: a pilot indicator set from the Doing Business project, World Bank.

The World Bank Group (2008). The welfare impact of rural electrification: A reassessment of the costs and benefits. An Independent Evaluation Group No. 6519. The World Bank, Washington, D.C. 